\title{
The Establishment of the Household Air Pollution Consortium (HAPCO)
}

H. Dean Hosgood III 1,*(D), Madelyn Klugman ${ }^{1}(\mathbb{D})$, Keitaro Matsuo ${ }^{2} \mathbb{D}$, Alexandra J. White ${ }^{3}$, Atsuko Sadakane ${ }^{4}$ (D) Xiao-Ou Shu ${ }^{5}$, Ruy Lopez-Ridaura ${ }^{6}$, Aesun Shin ${ }^{7}$ (D), Ichiro Tsuji ${ }^{8}$, Reza Malekzadeh ${ }^{9}{ }^{\mathbb{D}}$, Nolwenn Noisel ${ }^{10} \mathbb{D}$, Parveen Bhatti ${ }^{11}$, Gong Yang ${ }^{12}$, Eiko Saito ${ }^{13}(\mathbb{D}$, Shafiur Rahman ${ }^{14}{ }^{(D}$, Wei Hu ${ }^{15}$, Bryan Bassig ${ }^{15}$, George Downward ${ }^{16}$, Roel Vermeulen ${ }^{16} \mathbb{D}_{\text {, }}$ Xiaonan Xue ${ }^{1}$, Thomas Rohan ${ }^{1}$, Sarah K. Abe ${ }^{17}$, Philippe Broët ${ }^{10}$, Eric J. Grant ${ }^{4}$, Trevor J. B. Dummer ${ }^{18}$, Nat Rothman ${ }^{15}$, Manami Inoue ${ }^{17}(\mathbb{D}$, Martin Lajous 6,19, Keun-Young Yoo ${ }^{7}$, Hidemi Ito ${ }^{2}$, Dale P. Sandler ${ }^{3}$, Habib Ashan ${ }^{20,+}$, Wei Zheng ${ }^{12,+}$, Paolo Boffetta $21,22,+$ and Qing Lan $15,+$

1 Department of Epidemiology and Population Health, Albert Einstein College of Medicine, Bronx, NY 10461, USA

2 Division of Epidemiology and Prevention, Aichi Cancer Center Research Institute; Nagoya 464-8681, Japan

3 Epidemiology Branch, National Institute of Environmental Health Science, Research Triangle Park, NC 27709, USA

4 Department of Epidemiology, Radiation Effects Research Foundation, Hiroshima 732-0815, Japan

5 Division of Epidemiology, Department of Medicine, Vanderbilt University School of Medicine, Vanderbilt University Medicine Center, Nashville, TN 37203-1738, USA

6 National Institute of Public Health, Cuernavaca, Morelos 62100, Mexico

7 Department of Preventative Medicine, Seoul National University College of Medicine, Seoul 03080, Korea

8 Division of Epidemiology, Department of Health Informatics and Public Health, Tohoku University Graduate School of Medicine, Miyagi 980-8575, Japan

9 Digestive Diseases Research Institute, Tehran University of Medical Sciences, Tehran 14117, Iran

10 CARTaGENE, Centre de Recherche du CHU Sainte-Justine, Montreal, QC H3T 1C5, Canada

11 BC Cancer, Vancouver, BC V5Z 1L3, Canada

12 Center for Health Services, Vanderbilt University School of Medicine, Nashville, TN 37203-1738, USA

13 Division of Cancer Statistics and Integration, Center for Cancer Control and Information Services, National Cancer Center, Tokyo 104-0045, Japan

14 Department of Global Health Policy, Graduate School of Medicine, University of Tokyo, Tokyo 113-8654, Japan

15 Occupational and Environmental Epidemiology Branch, Division of Cancer Epidemiology and Genetics, National Cancer Institute, Bethesda, MD 20892-7240, USA

16 Institute for Risk Assessment Services, Utrecht University, 3508 Utrecht, The Netherlands

17 Epidemiology and Prevention Group, Center for Public Health Sciences, National Cancer Center, Tokyo 104-0045, Japan

18 School of Population and Public Health, University of British Columbia, Vancouver, BC V6T 1Z3, Canada

19 Department of Global Health and Population, Harvard T.H. Chan School of Public Health, Boston, MA 02115, USA

20 Department of Health Sciences, The University of Chicago, Chicago, IL 60637, USA

21 The Tisch Cancer Institute, Mount Sinai School of Medicine, New York, NY 10029-6574, USA

22 Department of Medical and Surgical Sciences, University of Bologna, 40126 Bologna, Italy

* Correspondence: dean.hosgood@einstein.yu.edu; Tel.: +1-718-430-2138

+ These authors share senior authorship.

Received: 30 May 2019; Accepted: 17 July 2019; Published: 23 July 2019

check for updates

Abstract: Household air pollution (HAP) is of public health concern, with $\sim 3$ billion people worldwide (including $>15$ million in the US) exposed. HAP from coal use is a human lung carcinogen, yet the epidemiological evidence on carcinogenicity of HAP from biomass use, primarily wood, is not conclusive. To robustly assess biomass's carcinogenic potential, prospective studies of individuals 
experiencing a variety of HAP exposures are needed. We have built a global consortium of 13 prospective cohorts (HAPCO: Household Air Pollution Consortium) that have site- and disease-specific mortality and solid fuel use data, for a combined sample size of 587,257 participants and 57,483 deaths. HAPCO provides a novel opportunity to assess the association of HAP with lung cancer death while controlling for important confounders such as tobacco and outdoor air pollution exposures. HAPCO is also uniquely positioned to determine the risks associated with cancers other than lung as well as nonmalignant respiratory and cardiometabolic outcomes, for which prospective epidemiologic research is limited. HAPCO will facilitate research to address public health concerns associated with HAP-attributed exposures by enabling investigators to evaluate sex-specific and smoking status-specific effects under various exposure scenarios.

Keywords: pollution; environmental exposures; biomass; cohort studies; consortium; cancer

\section{Introduction}

Exposure to household air pollution (HAP), created by the combustion of coal, wood, and other forms of biomass for heating and cooking, is experienced by approximately 3 billion people worldwide [1] and causes over 3.5 million deaths per year [2,3]. In addition, one of its major components, polycyclic aromatic hydrocarbons (PAHs), is a known carcinogen [4]. Some of the strongest evidence on lung cancer caused by HAP is based on studies in Xuanwei, China. Xuanwei is ideal to study HAP-attributed lung cancer due to its high incidence rate of female lung cancer $(\sim 120$ per 100,000 women) [5] combined with the fact that most women are never-smokers with substantial HAP exposures [6,7]. In Xuanwei, coal burning is associated with increased lung cancer risk [8], and improving stoves to mitigate HAP exposure is associated with significant reductions in lung cancer risk and lung cancer mortality [6,7]. A meta-analysis ( $>10,000$ cases; $>10,000$ controls) of studies from Asia, Africa, Europe, and North America confirmed that significant increased risk of incident lung cancer was observed not only for coal burning in Southwestern China, which includes Xuanwei, but in areas throughout the world [Odds Ratio(OR) $=2.15 ; 95 \%$ confidence interval $(\mathrm{CI})=1.61-2.89 ; \mathrm{n}=25)$ ], particularly in Asia (OR $=2.27 ; 95 \% \mathrm{CI}=1.65-3.12 ; \mathrm{n}=20)$ [9].

The International Agency for Research on Cancer (IARC) has classified HAP from indoor emissions from household coal combustion as a Group 1 human lung carcinogen [10]. However, due to limited epidemiologic evidence, IARC has classified HAP from biomass, primarily wood, as a probable human carcinogen (Group 2A) [11]. In an analysis pooling seven case-control studies [12], it was suggested that individuals using wood to heat their homes experienced a higher risk of lung cancer than individuals who used nonsolid fuels to heat their homes. With over 2.5 billion people exposed to wood smoke [1,10], and its increasing use for home heating in the US (over 15 million citizens currently exposed) [13], studies investigating the link between household wood smoke exposure and lung cancer are of tremendous importance.

Beyond the question of the pulmonary carcinogenicity of biomass, research priorities include elucidating the associations between HAP and cancer at other anatomical sites [14]. Retrospective studies have suggested that risk of cancers of the upper aero-digestive tract may be associated with exposures attributed to HAP. A review of 18 published studies evaluating the associations between HAP and cancers other than the lung found that HAP was associated with cervical, oral, nasopharyngeal, pharyngeal, and laryngeal cancers [15]. The observed associations between HAP and upper aero-digestive tract cancers remained significantly elevated when analyses were restricted to studies that controlled for smoking. In addition, a case-control study published subsequent to the meta-analysis found an association between HAP and breast cancer [16]. These associations, however, are considered preliminary, as most studies had limited sample size and all were retrospective in design. Moreover, additional research is needed to robustly assess the nonmalignant health outcomes that 
have been reported in the literature to be associated with the use of solid fuel for heating and cooking in the home. Several systematic reviews have assessed the association between HAP exposures and chronic diseases other than cancer, including respiratory and cardiovascular diseases [17-21]. Similar to systematic reviews of the existing cancer literature, these reviews observed inconclusive findings and that the literature is limited in scope with regards to prospective studies as well as a variety of exposure scenarios.

There is a need for large-scale prospective data that can assess the relationship between HAP and health outcomes while adjusting for important demographic and clinical factors. However, most prospective studies are limited in the number of ascertained disease outcomes. A consortium effort that brings together multiple prospective studies may lead to a sufficient number of cases of malignant and nonmalignant diseases to assess many of the previously mentioned HAP-disease relationships that have been inconclusive in the literature to date.

\section{Materials and Methods}

Prospective longitudinal cohort studies provide an excellent opportunity to assess the impact of HAP on chronic disease. To accurately quantify the relative and absolute risks of carcinogenic and cardiometabolic diseases associated with HAP exposure, particularly biomass-derived, we have established the Household Air Pollution Consortium (HAPCO). To date, 13 cohorts have agreed to participate (Table 1). These cohorts include: Three Prefecture Cohort Study Aichi (Aichi) [22], British Columbia Generations Project (BCGP) [23], CARTaGENE (CaG) [24], Golestan Cohort (GCS) [25], Health Effects of Arsenic Longitudinal Study (HEALS) [26], Korea Multicenter Cancer Cohort (KMCC) [27], Three Prefecture Cohort Study Miyagi (Miyagi) [22], Mexican Teachers Cohort (MTC) [28], RERF life-span study (RERF) [29], Sister Study (SIS) [30], Shanghai Men's Health Study (SMHS) [31], Shanghai Women's Health Study (SWHS) [32], and Xuanwei Cohort Study (XW) [6]. Almost all cohorts have accrued more than 5 years of follow-up data (with many having accrued 10-20 years) and all cohorts have more than 15,000 participants. In all cohorts, participants filled out baseline questionnaires that collected information about, among many other things, their fuel use for heating and cooking.

Given that no direct HAP exposure air monitoring measurements are available beyond the questionnaires, the baseline questionnaires were used to initially categorize individuals from each cohort into ever/never solid fuel users for heating or cooking in the home. Eight studies directly asked each participant if they have ever used solid fuels in their homes for heating or cooking. This variable was used to classify participants as ever/never users in these studies. In the remaining studies, individuals with high exposure levels were classified as ever exposed and individuals with low exposure levels were classified as never exposed. For two studies, those with any years of coal or wood use were classified as ever users, while those with zero years of use were classified as never users. For three studies, the ever users were those who used solid fuel in a stove without a chimney, and the never users were those who used a stove with a chimney. As described below, future aims of HAPCO include refining these harmonized exposure variables and possibly correlating questionnaire data with quantified biomarkers of HAP exposure (i.e., urinary PAH levels). 
Table 1. Characteristics of Cohorts Participating in HAPCO (Household Air Pollution Consortium).

\begin{tabular}{|c|c|c|c|c|c|c|c|c|c|c|c|c|c|c|c|}
\hline \multirow[t]{2}{*}{ Cohort (Abbreviation) } & \multirow[t]{2}{*}{ Country } & \multirow[t]{2}{*}{$\begin{array}{l}\text { Enrollment } \\
\text { Dates }\end{array}$} & \multirow[t]{2}{*}{$\begin{array}{c}\text { Total } \\
\text { Subjects }\end{array}$} & \multicolumn{2}{|c|}{ Males } & \multicolumn{2}{|c|}{ Females } & \multicolumn{2}{|c|}{ Never Smokers } & \multicolumn{2}{|c|}{ Ever Smokers } & \multicolumn{2}{|c|}{ Age at Baseline } & \multicolumn{2}{|c|}{ BMI at Baseline $\left(\mathrm{kg} / \mathrm{m}^{2}\right.$} \\
\hline & & & & $\mathbf{N}$ & $\%$ & $\mathbf{N}$ & $\%$ & $\mathbf{N}$ & $\%$ & $\mathbf{N}$ & $\%$ & Mean & Range & Mean & Range \\
\hline Golestan Cohort (GCS) & Iran & $2004-2008$ & 50,045 & 21,221 & $42.4 \%$ & 28,824 & $57.6 \%$ & 39,035 & $78.0 \%$ & 11,010 & $22.0 \%$ & 52.1 & $40.0-75.0$ & 26.7 & $11.8-62.2$ \\
\hline $\begin{array}{c}\text { Health Effects of Arsenic Longitudinal } \\
\text { Study (HEALS) }\end{array}$ & Bangladesh & 2000-2002 & 16,386 & 0 & $0.0 \%$ & 16,386 & $100.0 \%$ & 13,928 & $85.0 \%$ & 2458 & $15.0 \%$ & 37.1 & $17.0-75.0$ & 19.8 & $9.7-51.8$ \\
\hline $\begin{array}{l}\text { Korea Multi-center Cancer Cohort } \\
\text { (KMCC) }\end{array}$ & Korea & 1993-2004 & 20,636 & 8235 & $39.9 \%$ & 12,401 & $60.1 \%$ & 12,819 & $62.1 \%$ & 7471 & $36.2 \%$ & 54.1 & $15.0-99.0$ & 23.1 & $9.7-51.8$ \\
\hline RERF life-span study (RERF) & Japan & 1963-1993 & 52,883 & 20,390 & $38.6 \%$ & 32,493 & $61.4 \%$ & 28,408 & $53.7 \%$ & 22,102 & $41.8 \%$ & 52.2 & $19.3-98.7$ & 21.7 & $10.4-74.0$ \\
\hline Shanghai Men's Health Study (SMHS) & China & 2002-2006 & 25,958 & 25,958 & $100.0 \%$ & 0 & $0.0 \%$ & 9046 & $34.8 \%$ & 16,912 & $65.2 \%$ & 59.3 & $40.1-75.0$ & 23.9 & $11.6-40.3$ \\
\hline Shangai Women's Health Study (SWHS) & China & 1996-2000 & 74,942 & 0 & $0.0 \%$ & 74,942 & $100.0 \%$ & 72,829 & $97.2 \%$ & 2113 & $2.8 \%$ & 52.6 & $40.0-71.0$ & 24.0 & $12.7-49.0$ \\
\hline $\begin{array}{l}\text { Three Prefecture Cohort Study Aichi } \\
\text { (Aichi) }\end{array}$ & Japan & 1985 & 33,529 & 15,746 & $47.0 \%$ & 17,783 & $53.0 \%$ & 15,285 & $45.6 \%$ & 15,723 & $46.9 \%$ & 56.4 & $40.0-103.0$ & 22.1 & $10.6-57.0$ \\
\hline $\begin{array}{l}\text { Three Prefecture Cohort Study Miyagi } \\
\text { (Miyagi) }\end{array}$ & Japan & 1984 & 31,345 & 13,992 & $44.6 \%$ & 17,353 & $55.4 \%$ & 12,704 & $40.5 \%$ & 18,641 & $59.5 \%$ & 57.3 & $40.0-98.0$ & 23.2 & $7.2-64.9$ \\
\hline Xuanwei Cohort Study (XW) & China & 1992-1996 & 42,422 & 21,701 & $51.2 \%$ & 20,721 & $48.8 \%$ & 22,351 & $52.7 \%$ & 20,071 & $47.3 \%$ & 39.5 & $25.0-59.0$ & & ilable \\
\hline \multicolumn{3}{|c|}{ Sub-Totals for Cohorts in Asia } & 348,146 & 127,243 & $36.5 \%$ & 220,903 & $63.5 \%$ & 214,520 & $61.6 \%$ & 97,773 & $28.1 \%$ & & & & \\
\hline $\begin{array}{l}\text { British Columbia Generations Project } \\
\text { (BCGP) }\end{array}$ & Canada & 2008-2016 & 29,852 & 9345 & $31.3 \%$ & 20,462 & $68.5 \%$ & 15,321 & $51.3 \%$ & 13,412 & $44.9 \%$ & 56.4 & $31.0-74.0$ & 26.4 & $10.3-62.1$ \\
\hline CARTaGENE (CaG) & Canada & 2009-2016 & 43,061 & 19,249 & $44.7 \%$ & 23,812 & $55.3 \%$ & 17,259 & $40.1 \%$ & 23,434 & $54.4 \%$ & 53.6 & $38.3-73.1$ & 27.6 & $11.3-125.1$ \\
\hline Mexican Teachers Cohort (MTC) & Mexico & 2006-2008 & 115,314 & 0 & $0.0 \%$ & 115,314 & $100.0 \%$ & 90,061 & $78.1 \%$ & 25,254 & $21.9 \%$ & 43.0 & $20.0-84.0$ & 27.4 & $10.2-57.8$ \\
\hline Sister Study (SIS) & United States & 2003-2009 & 50,884 & 0 & $0.0 \%$ & 50,884 & $100.0 \%$ & 26,969 & $53.0 \%$ & 23,915 & $47.0 \%$ & 55.6 & $35.0-76.5$ & 27.8 & $11.5-72.1$ \\
\hline \multicolumn{3}{|c|}{ Sub-Totals for Cohorts in North America } & 239,111 & 28,594 & $12.0 \%$ & 210,472 & $88.0 \%$ & 149,610 & $62.6 \%$ & 86,015 & $36.0 \%$ & & & & \\
\hline \multicolumn{3}{|c|}{ Totals for all Cohort Contributing Data } & 587,257 & 155,837 & $26.5 \%$ & 431,375 & $73.5 \%$ & 364,130 & $62.0 \%$ & 183,788 & $31.3 \%$ & & & & \\
\hline
\end{tabular}




\section{Results}

In total, there are data from 587,257 participants (348,146 participants in cohorts conducted in Asia; 239,111 participants in cohorts conducted in North America), of whom 73.5\% are females (220,903 females in cohorts conducted in Asia; 210,472 females in cohorts conducted in North America) and $62.0 \%$ are never-smokers (214,520 never-smokers in cohorts conducted in Asia; 149,610 never-smokers in cohorts conducted in North America) (Table 1). Overall, the mean age at baseline among all cohorts tended to be in the mid-50s, except for HEALS, XW, and MTC, which were slightly younger. The average body mass index (BMI) at baseline tended to be lower among the cohorts conducted in Asia compared with those conducted in North America. Given the maturity of many of these cohorts, there has been a large number of deaths $(n=57,483)$. To date, there have been a total of 8,347 lung cancer deaths, as well as 306 oral and nasopharyngeal, 852 esophageal, and 154 laryngeal cancer deaths (Table 2). There have also been a total of 25,465 cardiovascular deaths.

Table 2. Number of selected cancer-related deaths in HAPCO (Household Air Pollution Consortium).

\begin{tabular}{cccccccc}
\hline \multirow{2}{*}{ Cohort Location } & \multicolumn{3}{c}{ Lung } & & Oral and Nasopharyngeal & Esophageal & Laryngeal \\
\cline { 2 - 8 } & Men & Women & All & All & All & All \\
\hline Asia & 4694 & 3478 & 8172 & 293 & 832 & 147 \\
North America & 113 & 62 & 175 & 13 & 20 & 7 \\
\hline All Cohorts & $\mathbf{4 8 0 7}$ & $\mathbf{3 5 4 0}$ & $\mathbf{8 3 4 7}$ & $\mathbf{3 0 6}$ & $\mathbf{8 5 2}$ & $\mathbf{1 5 4}$ \\
\hline
\end{tabular}

About a third of all subjects experienced HAP attributed to solid fuel use (Table 3). The prevalence of biomass (wood) use was $18.6 \%$ in all cohorts (25.3\% in cohorts conducted in Asia, $8.8 \%$ in cohorts conducted in North America), and coal use was 13.4\% (26.2\% in cohorts conducted in Asia, 2.1\% in cohorts conducted in North America). Regarding additional data available for harmonization, the number of years of use for each fuel type is available for $73 \%$ of subjects, and data related to the presence of ventilation in the vicinity of the fuel use and the type of stove used are available for $70 \%$ of subjects (Table 4 ).

Table 3. Prevalence of household air pollution exposures in HAPCO (Household Air Pollution Consortium).

\begin{tabular}{cccccccccc}
\hline $\begin{array}{c}\text { Cohort } \\
\text { Location }\end{array}$ & All Subjects & \multicolumn{2}{c}{ Clean Fuel + Users } & \multicolumn{2}{c}{ Coal Users } & \multicolumn{2}{c}{ Biomass Users } & Solid Fuel $¥$ Users \\
\cline { 2 - 9 } & $\mathbf{n}$ & $\mathbf{n}$ & $\mathbf{\%}$ & $\mathbf{n}$ & $\mathbf{\%}$ & $\mathbf{n}$ & $\mathbf{\%}$ & $\mathbf{n}$ & $\mathbf{\%}$ \\
\hline Asia & 348,146 & 162,963 & $46.8 \%$ & 91,067 & $26.2 \%$ & 88,134 & $25.3 \%$ & 178,965 & $51.4 \%$ \\
North America & 239,111 & 226,870 & $94.9 \%$ & 4942 & $2.1 \%$ & 21,045 & $8.8 \%$ & 25,987 & $10.9 \%$ \\
\hline All Cohorts & $\mathbf{5 8 7 , 2 5 7}$ & $\mathbf{3 8 1 , 1 2 9}$ & $\mathbf{6 4 . 9} \%$ & $\mathbf{7 8 , 7 5 5}$ & $\mathbf{1 3 . 4 \%}$ & $\mathbf{1 0 9 , 1 7 9}$ & $\mathbf{1 8 . 6} \%$ & $\mathbf{1 8 7 , 6 9 8}$ & $\mathbf{3 2 . 0} \%$ \\
\hline
\end{tabular}

† includes all non-solid fuels (i.e., electric, gas); ¥ includes coal and biomass users, which are not mutally exclusive (i.e., some individuals use both coal and biomass).

Table 4. Data available in each HAPCO (Household Air Pollution Consortium) cohort.

\begin{tabular}{|c|c|c|c|c|c|c|c|c|c|c|c|c|c|}
\hline & HEALS & SWHS & GCS & KMCC & Aichi & Miyagi & RERF & XW & $\mathrm{CaG}$ & BCGP & MTC & SIS & SMHS \\
\hline Age at Baseline (years) & $\sqrt{ }$ & $\sqrt{ }$ & $\sqrt{ }$ & $\sqrt{ }$ & $\sqrt{ }$ & $\sqrt{ }$ & $\sqrt{ }$ & $\sqrt{ }$ & $\sqrt{ }$ & $\sqrt{ }$ & $\sqrt{ }$ & $\sqrt{ }$ & $\sqrt{ }$ \\
\hline BMI at Baseline $\left(\mathrm{kg} / \mathrm{m}^{2}\right)$ & $\sqrt{ }$ & $\sqrt{ }$ & $\sqrt{ }$ & $\sqrt{ }$ & $\sqrt{ }$ & $\sqrt{ }$ & $\sqrt{ }$ & & $\sqrt{ }$ & $\sqrt{ }$ & $\sqrt{ }$ & $\sqrt{ }$ & $\sqrt{ }$ \\
\hline Educational Attainment & $\sqrt{ }$ & $\sqrt{ }$ & $\sqrt{ }$ & $\sqrt{ }$ & $\sqrt{ }$ & $\sqrt{ }$ & $\sqrt{ }$ & $\sqrt{ }$ & $\sqrt{ }$ & $\sqrt{ }$ & $\sqrt{ }$ & $\sqrt{ }$ & $\sqrt{ }$ \\
\hline Pack-years smoked & $\sqrt{ }$ & $\sqrt{ }$ & $\sqrt{ }$ & $\sqrt{ }$ & $\sqrt{ }$ & $\sqrt{ }$ & $\sqrt{ }$ & $\sqrt{ }$ & $\sqrt{ }$ & $\sqrt{ }$ & $\sqrt{ }$ & $\sqrt{ }$ & $\sqrt{ }$ \\
\hline Solid Fuel Use & $\sqrt{ }$ & $\sqrt{ }$ & $\sqrt{ }$ & $\sqrt{ }$ & $\sqrt{ }$ & $\sqrt{ }$ & $\sqrt{ }$ & $\sqrt{ }$ & $\sqrt{ }$ & $\sqrt{ }$ & $\sqrt{ }$ & $\sqrt{ }$ & $\sqrt{ }$ \\
\hline Fuel Type & $\sqrt{ }$ & $\sqrt{ }$ & $\sqrt{ }$ & $\sqrt{ }$ & $\sqrt{ }$ & $\sqrt{ }$ & $\sqrt{ }$ & $\sqrt{ }$ & $\sqrt{ }$ & $\sqrt{ }$ & $\sqrt{ }$ & $\sqrt{ }$ & $\sqrt{ }$ \\
\hline Stove Type & $\sqrt{ }$ & $\sqrt{ }$ & $\sqrt{ }$ & $\sqrt{ }$ & $\sqrt{ }$ & $\sqrt{ }$ & & $\sqrt{ }$ & $\sqrt{ }$ & $\sqrt{ }$ & & $\sqrt{ }$ & $\sqrt{ }$ \\
\hline $\mathrm{OAP}\left(\mathrm{NO}_{2}, \mathrm{PM}_{2.5}\right)$ & $¥$ & $¥$ & $¥$ & $¥$ & $¥$ & $¥$ & $¥$ & $¥$ & $\sqrt{ }$ & $\sqrt{ }$ & $¥$ & $\sqrt{ }$ & $¥$ \\
\hline
\end{tabular}


The original, baseline questionnaire data from the cohorts will be harmonized to allow for pooling of the HAP exposures in terms of the intensity and duration of exposure. Each HAPCO cohort has the covariate data for our analyses (Table 4), such as age, gender, active tobacco smoking, education, and BMI. These variables will be harmonized to ensure comparability across cohorts. For example, active tobacco smoking will be first classified broadly (ever, never), where never-smoking is defined has not having smoked more than 100 cigarettes in their lifetime. Smoking will also be assessed by years of smoking and packs-years smoked. Finally, years since quitting smoking will also be harmonized, which will also allow for classification of individuals as current, former, and never-smokers. In addition to these covariates, OAP exposures will be estimated by GIS-based methods that link geocoded residential addresses to exposure databases. Outdoor air pollution estimates will be available for all cohorts either through local models and/or via the global air pollution maps for $\mathrm{PM}_{2.5}$ and $\mathrm{NO}_{2}$. The $\mathrm{CaG}$ and BCGP cohorts are covered by air pollution exposure surfaces as generated and collated within the Canadian Urban Environmental Health Research Consortium (CANUE) [33]. The SIS cohort has already estimated $\mathrm{PM}_{2.5}$ and $\mathrm{NO}_{2}$ concentration through national, satellite-based models [34]. $\mathrm{PM}_{2.5}$ and $\mathrm{NO}_{2}$ concentrations for the other cohorts are currently being derived using satellite-based estimates as well as from available ground-level monitoring data [35]. Once data harmonization is complete, the mortality rates of each disease outcome of interest will be assessed overall, by sex and by smoking status. Next, the associations between HAP exposure and mortality from lung, esophageal, oral, pharyngeal, and laryngeal cancers, by smoking status and sex, will be assessed.

\section{Conclusions}

HAPCO currently involves 13 cohorts from eight countries on two continents. Major strengths of HAPCO include the use of prospectively designed studies that substantially mitigate recall and temporal biases, as well as the large sample size lending itself to high statistical power. A collaborative data harmonization procedure for exposures, potential confounders, and outcomes will be developed for accurate estimation of magnitude and type of HAP exposure. By providing this platform, HAPCO will facilitate research by investigators to address public health concerns associated with HAP-attributed exposures. A robust assessment of exposures may serve to better predict risk of cancer and/or cardiovascular disease, which may impact future local, regional, and national policies. Future aims of HAPCO are to (1) identify additional cohort studies to join the consortium, particularly cohorts conducted in Africa and South America, where solid fuel use remains prevalent, and (2) quantitatively assess potential biomarkers for HAP exposure. HAPCO also welcomes additional project proposals from interested researchers. Such proposals will be reviewed by, and individually approved by, each cohort before access to the respective cohort data can be facilitated by HAPCO. These studies will have the potential to inform future interventions to reduce disease burden in global populations.

Author Contributions: This project was conceived by H.D.H.III, R.V., N.R., P.B. (Paolo Boffetta), and Q.L.; Cohort-specific data and analyses were provided by K.M., A.J.W., A.S. (Atsuko Sadakane), X.-O.S., A.S. (Aesun Shin), I.T., R.M., N.N., P.B. (Parveen Bhatti), G.Y., W.H., B.B., P.B. (Philippe Broët), E.J.G., T.J.B.D., M.L., K.-Y.Y., H.I., G.D., H.A., W.Z., P.B. (Paolo Boffetta), Q.L.; Data curation was by H.D.H.III, M.K., E.S., S.R., and M.I.; The manuscript was prepared by H.D.H.III, M.K., X.X., and T.R. Critical review on the manuscript was by K.M., A.J.W., A.S. (Atsuko Sadakane), R.L.-R., A.S. (Aesun Shin), I.T., R.M., N.N., P.B. (Parveen Bhatti), G.Y., E.S., S.R., W.H., B.B., R.V., S.K.A., P.B. (Philippe Broët), E.J.G., T.J.B.D., N.R., M.I., M.L., K.-Y.Y., H.I., D.P.S., H.A., W.Z., P.B. (Paolo Boffetta), and Q.L.

Funding: This works was funded in part by the Albert Einstein College of Medicine's Global Health Center, the Intramural Research Program of the NIH, National Institute of Environmental Health Sciences (Z01-ES044005) (Sisters Study), and NCI CA210286-01 (Mexican Teachers Cohort). The Radiation Effects Research Foundation (RERF), Hiroshima and Nagasaki, Japan is a public interest foundation funded by the Japanese Ministry of Health, Labor, and Welfare (MHLW) and the US Department of Energy (DOE). The BC Generations cohort was made possible through financial support from the Canadian Partnership Against Cancer and Health Canada and the BC Cancer Foundation.

Conflicts of Interest: The authors declare no conflict of interest. 


\section{References}

1. Ezzati, M.; World Health Organization. Comparative Quantification of Health Risks: Global and Regional Burden of Disease Attributable to Selected Major Risk Factors; World Health Organization: Geneva, Switzerland, 2004.

2. Smith, K.R.; Bruce, N.; Balakrishnan, K.; Adair-Rohani, H.; Balmes, J.; Chafe, Z.; Dherani, M.; Hosgood, H.D.; Mehta, S.; Pope, D.; et al. Millions dead: How do we know and what does it mean? Methods used in the comparative risk assessment of household air pollution. Annu. Rev. Public Health 2014, 35, 185-206. [CrossRef] [PubMed]

3. Gakidou, E.; Afshin, A.; Abajobir, A.A.; Abate, K.H.; Abbafati, C.; Abbas, K.M.; Abd-Allah, F.; Abdulle, A.M.; Abera, S.F.; Aboyans, V.; et al. Global, regional, and national comparative risk assessment of 84 behavioural, environmental and occupational, and metabolic risks or clusters of risks, 1990-2016: A systematic analysis for the Global Burden of Disease Study 2016. Lancet 2017, 390, 1345-1422. [CrossRef]

4. IARC Working Group on the Evaluation of Carcinogenic Risk to Humans. Some Non-heterocyclic Polycyclic Aromatic Hydrocarbons and Some Related Exposures. In IARC Monographs on the Evaluation of Carcinogenic Risks to Humans; International Agency for Research on Cancer: Lyon, France, 2010; Volume 92.

5. Xiao, Y.; Shao, Y.; Yu, X.; Zhou, G. The epidemic status and risk factors of lung cancer in Xuanwei City, Yunnan Province, China. Front. Med. 2012, 6, 388-394. [CrossRef] [PubMed]

6. Lan, Q.; Chapman, R.S.; Schreinemachers, D.M.; Tian, L.; He, X. Household stove improvement and risk of lung cancer in Xuanwei, China. J. Natl. Cancer Inst. 2002, 94, 826-835. [CrossRef] [PubMed]

7. Hosgood, H.D.; Chapman, R.; Shen, M.; Blair, A.; Chen, E.; Zheng, T.; Lee, K.M.; He, X.; Lan, Q. Portable stove use is associated with lower lung cancer mortality risk in lifetime smoky coal users. Br. J. Cancer 2008, 99, 1934-1939. [CrossRef] [PubMed]

8. Lan, Q.; He, X.; Shen, M.; Tian, L.; Liu, L.Z.; Lai, H.; Chen, W.; Berndt, S.I.; Hosgood, H.D.; Lee, K.M.; et al. Variation in lung cancer risk by smoky coal subtype in Xuanwei, China. Int. J. Cancer 2008, 123, 2164-2169. [CrossRef] [PubMed]

9. Hosgood, H.D., 3rd; Wei, H.; Sapkota, A.; Choudhury, I.; Bruce, N.; Smith, K.R.; Rothman, N.; Lan, Q. Household coal use and lung cancer: Systematic review and meta-analysis of case-control studies, with an emphasis on geographic variation. Int. J. Epidemiol. 2011, 40, 719-728. [CrossRef]

10. IARC. Household Use of Solid Fuels and High-Temperature Frying; World Health Organization: Lyon, France, 2010; Volume 95.

11. Straif, K.; Baan, R.; Grosse, Y.; Secretan, B.; El Ghissassi, F.; Cogliano, V.; WHO International Agency for Research on Cancer Monograph Working Group. Carcinogenicity of household solid fuel combustion and of high-temperature frying. Lancet Oncol. 2006, 7, 977-978. [CrossRef]

12. Hosgood, H.D., 3rd; Boffetta, P.; Greenland, S.; Lee, Y.C.; McLaughlin, J.; Seow, A.; Duell, E.J.; Andrew, A.S.; Zaridze, D.; Szeszenia-Dabrowska, N.; et al. In-home coal and wood use and lung cancer risk: A pooled analysis of the International Lung Cancer Consortium. Environ. Health Perspect. 2010, 118, 1743-1747. [CrossRef]

13. Rogalsky, D.K.; Mendola, P.; Metts, T.A.; Martin, W.J., 2nd. Estimating the number of low-income americans exposed to household air pollution from burning solid fuels. Environ. Health Perspect. 2014, 122, 806-810. [CrossRef]

14. Reid, B.C.; Ghazarian, A.A.; DeMarini, D.M.; Sapkota, A.; Jack, D.; Lan, Q.; Winn, D.M.; Birnbaum, L.S. Research opportunities for cancer associated with indoor air pollution from solid-fuel combustion. Environ. Health Perspect. 2012, 120, 1495-1498. [CrossRef] [PubMed]

15. Josyula, S.; Lin, J.; Xue, X.; Rothman, N.; Lan, Q.; Rohan, T.E.; Hosgood, H.D., 3rd. Household air pollution and cancers other than lung: A meta-analysis. Environ. Health 2015, 14, 24. [CrossRef] [PubMed]

16. White, A.J.; Teitelbaum, S.L.; Stellman, S.D.; Beyea, J.; Steck, S.E.; Mordukhovich, I.; McCarty, K.M.; Ahn, J.; Rossner, P., Jr.; Santella, R.M.; et al. Indoor air pollution exposure from use of indoor stoves and fireplaces in association with breast cancer: A case-control study. Environ. Health Glob. Access Sci. Source 2014, 13, 108. [CrossRef] [PubMed]

17. Assad, N.A.; Balmes, J.; Mehta, S.; Cheema, U.; Sood, A. Chronic obstructive pulmonary disease secondary to household air pollution. Semin. Respir. Crit. Care Med. 2015, 36, 408-421. [CrossRef] [PubMed] 
18. Kurmi, O.P.; Sadhra, C.S.; Ayres, J.G.; Sadhra, S.S. Tuberculosis risk from exposure to solid fuel smoke: A systematic review and meta-analysis. J. Epidemiol. Community Health 2014, 68, 1112-1118. [CrossRef] [PubMed]

19. Jary, H.; Simpson, H.; Havens, D.; Manda, G.; Pope, D.; Bruce, N.; Mortimer, K. Household Air Pollution and Acute Lower Respiratory Infections in Adults: A Systematic Review. PLoS ONE 2016, 11, e0167656. [CrossRef] [PubMed]

20. Fatmi, Z.; Coggon, D. Coronary heart disease and household air pollution from use of solid fuel: A systematic review. Br. Med. Bull. 2016, 118, 91-109. [CrossRef]

21. West, S.K.; Bates, M.N.; Lee, J.S.; Schaumberg, D.A.; Lee, D.J.; Adair-Rohani, H.; Chen, D.F.; Araj, H. Is household air pollution a risk factor for eye disease? Int. J. Environ. Res. Public Health 2013, 10, 5378-5398. [CrossRef] [PubMed]

22. Marugame, T.; Sobue, T.; Satoh, H.; Komatsu, S.; Nishino, Y.; Nakatsuka, H.; Nakayama, T.; Suzuki, T.; Takezaki, T.; Tajima, K.; et al. Lung cancer death rates by smoking status: Comparison of the Three-Prefecture Cohort study in Japan to the Cancer Prevention Study II in the USA. Cancer Sci. 2005, 96, 120-126. [CrossRef] [PubMed]

23. Dhalla, A.; McDonald, T.E.; Gallagher, R.P.; Spinelli, J.J.; Brooks-Wilson, A.R.; Lee, T.K.; Lai, C.; Borugian, M.J.; Woods, R.R.; Le, N.D.; et al. Cohort Profile: The British Columbia Generations Project (BCGP). Int. J. Epidemiol. 2018. [CrossRef]

24. Awadalla, P.; Boileau, C.; Payette, Y.; Idaghdour, Y.; Goulet, J.P.; Knoppers, B.; Hamet, P.; Laberge, C. Cohort profile of the CARTaGENE study: Quebec's population-based biobank for public health and personalized genomics. Int. J. Epidemiol. 2013, 42, 1285-1299. [CrossRef] [PubMed]

25. Pourshams, A.; Khademi, H.; Malekshah, A.F.; Islami, F.; Nouraei, M.; Sadjadi, A.R.; Jafari, E.; Rakhshani, N.; Salahi, R.; Semnani, S.; et al. Cohort Profile: The Golestan Cohort Study-A prospective study of oesophageal cancer in northern Iran. Int. J. Epidemiol. 2010, 39, 52-59. [CrossRef] [PubMed]

26. Ahsan, H.; Chen, Y.; Parvez, F.; Argos, M.; Hussain, A.I.; Momotaj, H.; Levy, D.; van Geen, A.; Howe, G.; Graziano, J. Health Effects of Arsenic Longitudinal Study (HEALS): Description of a multidisciplinary epidemiologic investigation. J. Expo. Sci. Environ. Epidemiol. 2006, 16, 191-205. [CrossRef] [PubMed]

27. Yoo, K.Y.; Shin, H.R.; Chang, S.H.; Lee, K.S.; Park, S.K.; Kang, D.; Lee, D.H. Korean Multi-center Cancer Cohort Study including a Biological Materials Bank (KMCC-I). Asian Pac. J. Cancer Prev. 2002, 3, 85-92. [PubMed]

28. Lajous, M.; Ortiz-Panozo, E.; Monge, A.; Santoyo-Vistrain, R.; Garcia-Anaya, A.; Yunes-Diaz, E.; Rice, M.S.; Blanco, M.; Hernandez-Avila, M.; Willett, W.C.; et al. Cohort Profile: The Mexican Teachers' Cohort (MTC). Int. J. Epidemiol. 2015. [CrossRef] [PubMed]

29. Ozasa, K.; Shimizu, Y.; Suyama, A.; Kasagi, F.; Soda, M.; Grant, E.J.; Sakata, R.; Sugiyama, H.; Kodama, K. Studies of the mortality of atomic bomb survivors, Report 14, 1950-2003: An overview of cancer and noncancer diseases. Radiat. Res. 2012, 177, 229-243. [CrossRef] [PubMed]

30. Sandler, D.P.; Hodgson, M.E.; Deming-Halverson, S.L.; Juras, P.S.; D'Aloisio, A.A.; Suarez, L.M.; Kleeberger, C.A.; Shore, D.L.; DeRoo, L.A.; Taylor, J.A.; et al. The Sister Study Cohort: Baseline Methods and Participant Characteristics. Environ. Health Perspect. 2017, 125, 127003. [CrossRef] [PubMed]

31. Shu, X.O.; Li, H.; Yang, G.; Gao, J.; Cai, H.; Takata, Y.; Zheng, W.; Xiang, Y.B. Cohort Profile: The Shanghai Men's Health Study. Int. J. Epidemiol. 2015, 44, 810-818. [CrossRef]

32. Zheng, W.; Chow, W.H.; Yang, G.; Jin, F.; Rothman, N.; Blair, A.; Li, H.L.; Wen, W.; Ji, B.T.; Li, Q.; et al. The Shanghai Women's Health Study: Rationale, study design, and baseline characteristics. Am. J. Epidemiol. 2005, 162, 1123-1131. [CrossRef]

33. Hystad, P.; Demers, P.A.; Johnson, K.C.; Brook, J.; van Donkelaar, A.; Lamsal, L.; Martin, R.; Brauer, M. Spatiotemporal air pollution exposure assessment for a Canadian population-Based lung cancer case-Control study. Environ. Health 2012, 11, 22. [CrossRef] 
34. Chan, S.H.; Van Hee, V.C.; Bergen, S.; Szpiro, A.A.; DeRoo, L.A.; London, S.J.; Marshall, J.D.; Kaufman, J.D.; Sandler, D.P. Long-Term Air Pollution Exposure and Blood Pressure in the Sister Study. Environ. Health Perspect. 2015, 123, 951-958. [CrossRef] [PubMed]

35. Larkin, A.; Geddes, J.A.; Martin, R.V.; Xiao, Q.; Liu, Y.; Marshall, J.D.; Brauer, M.; Hystad, P. Global Land Use Regression Model for Nitrogen Dioxide Air Pollution. Environ. Sci. Technol. 2017, 51, 6957-6964. [CrossRef] [PubMed]

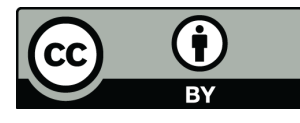

(C) 2019 by the authors. Licensee MDPI, Basel, Switzerland. This article is an open access article distributed under the terms and conditions of the Creative Commons Attribution (CC BY) license (http://creativecommons.org/licenses/by/4.0/). 